\section{P3.144 EVALUATING THE PREVALENCE AND KNOWLEDGE OF SEXUALLY TRANSMITTED INFECTION AMONG HOMELESS PERSONS IN CENTRAL BRAZIL}

Marcos André de Matos, Karlla Antonieta Amorim Caetano, Sheila Araujo Teles, Raquel Silva Pinheiro, Paulie Marcelly Ribeiro dos Santos Carvalho, Luana Rocha da Cunha Rosa, Márcia Maria de Souza, Ana Luiza Neto Junqueira, Brenda Kelly Gonçalves Nunes, Andressa Cunha Paula, Thaynara Ferreira de Amorim. Universidade Federal De Goiás, Goiânia - GO, Brazil

\subsection{6/sextrans-2017-053264.379}

Introduction The objective of this study was to estimate the prevalence of Sexually Transmitted Infections and to explore the general understanding of transmission and prevention of these infections among the homeless in Goiânia, Central Brazil.

Methods This is a cross-sectional study. Between August 2014 and June 2015, residents of a public homeless shelter were recruited in Goiânia, Goiás, in Central Brazil. Survey items included demographics and knowledge of STIs. Blood samples were submitted to rapid tests for HIV, syphilis, and hepatitis $\mathrm{B}(\mathrm{HBV})$, and a positive result on any one or more of these tests indicated the presence of an STI. This study was approved by the Research Ethics Committee of the Federal University of Goiás.

Results The sample included 209 homeless persons. The mean age of participants was 38 years. The prevalence of STI was 27.8\% (58/209), for HIV 3.3\% (7/209), syphilis 24.9\% (52/ $209)$ and hepatitis B $1.0 \%(2 / 209)$. When asked about transmission of HIV, syphilis, and hepatitis B in public restrooms, $4.8 \%, 8.6 \%$ and $10.5 \%$ reported that this can occur, respectively. On syringe sharing as an IST transmission route, $78 \%$, $11.5 \%$ and $23.9 \%$ believe that HIV, syphilis and hepatitis B can be acquired through this parenteral media, respectively. The male condom was investigated as a method of prevention for these sexual infections, and $73.7 \%, 38.3 \%$ and $14.4 \%$ affirmed the efficacy of condom use for protection against HIV, syphilis and hepatitis B, respectively. It was found that age (PR: 1.01 ; 95\% CI: $1.00-1.03$ ) and confirming HIV transmission through syringe sharing (PR: 0.47 ; 95\% CI: $0.27-$ $0.81)$ were statistically significant associated with STI positivity $(\mathrm{p} \leq 0.05)$.

Conclusion The dissemination of knowledge about STIs is an important tool for breaking the chain of transmission of sexual infections. In Brazil, access of the homeless population to health and sexuality education services can be improved using mobile health teams, known as Street Outreach Offices.

\section{P3.145 GENITAL CHLAMYDIA TRACHOMATIS INFECTIONS AMONG PATIENTS ATTENDING THE UNIVERSIDAD DE BUENOS AIRES HOSPITAL DURING 2010-2015}

Gallo Vaulet Maria Lucia, L Amaya, M Mestre, V Gualtieri, ML Gallo Vaulet, AC Entrocassi. Universidad de Buenos Aires, Facultad De Farmacia Y Bioquímica, Depto. Bioquímica Clínica, Buenos Aires, Argentina

\subsection{6/sextrans-2017-053264.380}

Introduction: Chlamydia trachomatis is the most prevalent bacterial sexually transmissible infection (STI) worldwide. Since the majority of the cases remain asymptomatic, lack of treatment can lead to serious sequels, principally in women. Previous studies at the University Hospital (period 2001-2009) reported a C. trachomatis prevalence of $2.1 \%$. The aim of this study was to analyse the prevalence of C. trachomatis infections in patients attending the University Hospital in the 2010-2015 period.

Methods All genital samples (cervical swabs, male urethral swabs and first void urine) taken from patients attending the University Hospital laboratory between $1 / 1 / 2010$ and 31/12/ 2015 with indication of $C$. trachomatis detection were included in this study. C. trachomatis was detected by ompA nested PCR. Genotyping of C. trachomatis was done by PCRRFLP.

Results A total of 2664 samples (1998 feminine and 666 masculine) were included in this study. Global prevalence of C. trachomatis was $2.25 \%$ (60/2664), $5.55 \%$ in males $(37 / 666)$ and $1.15 \%(23 / 1998)$ in females. Among C. trachomatis positive patients, $56.8 \%$ of male $(21 / 37)$ and $26.1 \%$ of female (6/ 23) patients were symptomatic. C. trachomatis prevalence was $13 \%$ at the STI clinic, $3.4 \%$ at the OBGYN clinic and $0.5 \%$ at the fertility program. Among male infected patients, $63.6 \%$ were under 30 years, and $47.8 \%$ of infected women were under 25 years. The most frequently detected genotype was E (35\%) followed by D (21\%) and F (13\%).

Conclusion Global prevalence of C. trachomatis did not change respect the 2001-2009 period. Comparing to 20012009 period, an increase in the frequency of infection in males was observed $(5.55 \%$ vs $3.29 \% \quad \mathrm{p}=0.07)$. Difference was observed in prevalence of infection in the OBGYN clinic vs Fertility Program $(3.4 \%$ vs $0.5 \% \mathrm{p}<0.05)$. Genotype distribution is similar to previously reported in this population and does not differ from international distribution. According to our results vulnerable populations for C. trachomatis infection are young and male symptomatic patients.

\section{P3.146 FIRST BRAZILIAN NATIONAL ANTIMICROBIAL SUSCEPTIBILITY SURVEILLANCE FOR NEISSERIA GONORRHOEAE}

${ }^{1}$ Maria Luiza Bazzo, 'Lisléia Golfetto, ${ }^{2}$ Miriam Franchini, ${ }^{2}$ Pâmela Cristina Gaspar, ${ }^{3}$ Ana Flávia Pires, ${ }^{4}$ Ligia MariaBedeschi Costa, ${ }^{5}$ Mauro Cunha Ramos, ${ }^{6}$ Loeci Natalina Timm, ${ }^{7}$ William Antunes Ferreira, ${ }^{8}$ Purificação Pereira da Silva Maria Da, ${ }^{9}$ Carvalho da Silva Roberto José, ${ }^{10}$ Fonseca Andrade Lidiane da, ${ }^{11}$ Fátima Mendes Pereira Lúcia de, ${ }^{1}$ Felipe de Rocco, ${ }^{1}$ Jéssica Martins, ${ }^{1}$ Hanalydia Machado, ${ }^{1}$ Marcos André Schörner, ${ }^{1}$ Thaís Mattos Santos, ${ }^{4}$ Faria de Carvalho Simone Veloso, ${ }^{4}$ Luciane Guimarães Dias, ${ }^{6}$ Letícia Eidt, ${ }^{6}$ de Oliveira Arnhold Guilherme Henrique, ${ }^{6}$ Souza Coelho Muniz Chayane Ariel, ${ }^{7}$ Waldemara de Souza Vasconcelos, ${ }^{7}$ Jairo de Souza Gomes, ${ }^{7}$ Pinto Da Silva Maria De Fátima, ${ }^{8}$ Rosan Barboza de Matos, Cláudio Campos do, ${ }^{9}$ Porto, ${ }^{12}$ Leonor Henriette de Lannoy, ${ }^{2}$ Adele Schwartz Benzaken. 'Federal University of Santa Catarina, Florianópolis - SC, Brazil, ${ }^{2}$ Department of Surveillance, Prevention and Control of STI, HIVIAIDS and Viral Hepatitis, Brasilia - DF, Brazil; ${ }^{3}$ Postgraduate Program In Collective Health Of University of Brasilia, Brasilia - DF, Brazil; ${ }^{4}$ Municipal Secretary of Health Belo Horizonte, Belo Horizonte - MG, Brazil; ${ }^{5}$ Brazilian Society of STD, Porto Alegre - RS, Brazil; ${ }^{6}$ State Department of Health of Rio Grande do Sul, Porto Alegre - RS, Brazil; ${ }^{7}$ Alfredo da Mata Foundation, Manaus - AM, Brazil; ${ }^{8}$ State Centre Specialised in Diagnosis, Assistance And Research, Salvador - BA, Brazil; ${ }^{9}$ STD Reference and Training Centre of São Paulo, São Paulo - SP, Brazil; ${ }^{10}$ Testing and Counselling Centre of Distrito Federal, Brasilia - DF, Brazil; ${ }^{11}$ Central Public Health Laboratory of Distrito Federal, Brasilia - DF, Brazil; ${ }^{12}$ Day Hospital of Brasilia, Brasilia - DF Brazil

\subsection{6/sextrans-2017-053264.381}

Introduction The threat of multidrug resistant Neisseria gonorrhoeae (NG) is a concern worldwide, especially in settings with emerging resistance to the extended spectrum cephalosporins. Since 2009 WHO recommendation to the countries to perform Antimicrobial Surveillance has been reinforced. Brazilian's sexually transmitted infection guideline recommends 
dual therapy to treat gonococcal infection (ciprofloxacin plus azithromycin). However, regional studies performed in three Brazilian states demonstrated quinolone resistance. For these states it was recommended to replace the quinolones by third generation cephalosporin. The aim of this study was to perform a Brazilian national gonococcal antimicrobial surveillance. Methods The surveillance study included seven collection sites representing five geographic regions of Brazil. A total of $550 \mathrm{NG}$ isolates from male urethral discharge was sent to the gonococcal national reference laboratory for analysis. The minimum inhibitory concentration (MIC) with the agar dilution method was performed for penicillin, tetracycline, ciprofloxacin, ceftriaxone, cefixime and azithromycin.

Results The sensitivity profile of the NG isolates was performed in 131 isolates from the Southeast, 104 from the Northeast, 100 from the North, 68 from the Center-West and 147 from the South. In addition to penicillin and tetracycline, a high level of resistance for ciprofloxacin $(47 \%$ to $78 \%$ of isolates) was observed in the isolates of all the regions. All the isolates were sensitive to ceftriaxone and cefixime, although one isolate was found with elevated MIC. Regarding azithromycin sensitivity, the majority of the isolates were sensitive, but the emergence of an intermediate $(5 \%$ to $15 \%)$ or resistant (4\% to $10 \%)$ profile needs to be monitored.

Conclusion The national survey confirmed the high level of ciprofloxacin resistance already described worldwide. These results indicate the need to urgently change Brazilian recommendation for gonorrhoeae treatment and the importance of systematic gonococcal resistance surveillance.

\section{P3.147 PREVALENCE OF SEXUALLY TRANSMITTED INFECTIONS AND ASSOCIATED FACTORS IN WOMEN WHO HAVE SEX WITH WOMEN}

MAO Ignacio, J Andrade, APF Freitas, MG Silva, MTC Duarte. São Paulo State University, Brazil

\subsection{6/sextrans-2017-053264.382}

Introduction The present research aims to fill a gap in the national and international literature concerning prevalences and factors related to STI (Sexually Transmitted Infections) in Women who Have Sex with Women (WSW).

Methods It is a cross sectional, analytical and non-radomized study with 100 WSW from Botucatu - SP and surrounding regions who answered the call from social media, mass communication means, health services and friends or acquaintances from January to November,2015. Data was obtained by the researchers involved in the main study, through interviews, blood tests to diagnose HIV, syphilis and hepatitis B and cervical sample collection to investigate Chlamydia Trachomatis, Neisseria Gonorrhoeae, HPV through PCR and oncotic cytology to screen Trichomonas vaginalis. Associations were estimated by multiple regression.

Results Total prevalence of STI was 35\%, chlamidia infection (3.3\%), HIV infection (2.0\%), Trichomonas vaginalis $(1.1 \%)$ and syphilis (1.0\%). Neisseria Gonorrhoeae and Hepatites B were not found. The factors associated to STI were: to be single, $[\mathrm{OR}=3,76$ (CI:95\%: 1.14-12.43); $\mathrm{p}=0030]$, use of sex toys $[\mathrm{OR}=3,87(\mathrm{CI}: 95 \%$ : $1.14-13.16) ; \mathrm{p}=0030]$, and number of male partners in the previous year $[\mathrm{OR}=7,99$ (CI:95\%: 1.51-42.44); $\mathrm{p}=0015]$.
Conclusion Considered as whole, these data lead to conclusion that the individuals of this study presented high vulnerability to STI/AIDS, as shown by the high prevalence of STI. This study clearly shows the need for a specific health assistance to these women, promoting prevention and education in a holistic approach.

\section{P3.148 REPORTED SEXUALLY TRANSMITTED INFECTIONS IN BRAZIL: PREVALENCE AND RISK FACTORS}

${ }^{1}$ Mariana Jorge De Queiroz, ${ }^{2}$ Meritxell Sabidó, ${ }^{1}$ Clarissa Habckost Dutra De Barros, ${ }^{1}$ Ana Roberta Pati Pascom, ${ }^{3}$ Enrique Galbán, ${ }^{1}$ Adele Schwartz Benzaken. 'Department of STI, AIDS and Viral Hepatitis, Secretary for Health Surveillance, Ministry of Health, Brasilia - DF, Brazil; ${ }^{2}$ University of Girona, Catalonia, Spain; ${ }^{3}$ Facultad de Medicine, Habana, Cuba

\subsection{6/sextrans-2017-053264.383}

Introduction Population-based studies help provide more-robust prevalence estimates and related factors, which are needed to drive sexually transmitted infection (STI) prevention and control programmes. We use data from the Brazilian Survey of Knowledge, Attitudes, and Practices (PCAP) to examine the prevalence of self-reported STIs and its association with demographics, behaviour, and the uptake of interventions.

Methods A probability sample survey was conducted in 2013 (PCAP-2013; $\mathrm{n}=12,000)$ and in 2008 (PCAP-2008; $\mathrm{n}=8,000)$ among men and women aged 15-64. The participants completed the survey in their homes through computer-assisted face-to-face interviews and self-interviews. We describe the age-specific and sex-specific prevalence of self-reported STIs in relation to demographics, behavioural factors, and the uptake of interventions and explore associated changes since the PCAP-2008.

Results Overall, 9.4\% of men and 5.3\% of women reported having had an STI in 2013. This prevalence decreased from that in 2008 (15.9\% in men and $8.8 \%$ in women). In 2013, self-reported STIs were mainly urethral discharge $(5.8 \%)$ among men and genital ulcers (2.9\%) among women. Men sought care and treatment more often than women did during their most recent experience of STI symptoms (care: $85.7 \%$ and $81.2 \%$; treatment: $77.5 \%$ and $68.7 \%$, respectively). Selfreported STI infections were associated with increasing age, decreasing socioeconomic status, current or previous drug use, sex with a casual partner in the last 12 months (for both sexes), sex with a same sex partner, and no condom use during the last sexual intercourse (for men), and non-indigenous status and one or more previous HIV tests (for women).

Conclusion This probability sample survey highlights a decrease in STIs for men and women in Brazil. Women carry a higher STI burden than men do. The increases in health care-seeking behaviour and treatment received when presenting symptoms are encouraging. Increasing age, casual sexual partners, and drug use are the main risk factors for STI acquisition.

\section{P3.149 SPATIOTEMPORAL DYNAMICS OF THE HIV EPIDEMIC IN BRAZIL, 2009 TO 2014}

Mariana Veloso Meireles, Ana Roberta Pati Pascom. Department of STIS, AIDS And Viral Hepatitis/Ministry of Health of Brazil, Brasilia - DF, Brazil

10.1136/sextrans-2017-053264.384 